\title{
Density-dependent migration in an Amphiura filiformis (Amphiuridae, Echinodermata) infaunal population
}

\author{
Rutger Rosenberg*, Hans C. Nilsson, Karin Hollertz, Birthe Hellman \\ Department of Marine Ecology, Göteborg University, Kristineberg Marine Research Station, S-450 34 Fiskebäckskil, Sweden
}

\begin{abstract}
The hypothesis that the semi-mobile brittle star Amphiura filiformis may have densitydependent migratory behaviour and that their dispersion may be dependent on food availability was examined. Sediment with intact fauna dominated by A. filiformis $\left(-2250\right.$ ind. $\left.\mathrm{m}^{-2}\right)$ was brought to the laboratory in $0.22 \mathrm{~m}^{2}$ plexiglass boxes. The experiment was a 2 -factorial design with density (high or moderate) and food (fed in excess or starved) as factors. To investigate migration in the high and moderate densities, the abundance of A. filiformis was experimentally manipulated in the boxes at the start of the experiment to 'low' (100 ind. $\left.0.11 \mathrm{~m}^{-2}\right)$ numbers in one-half of all boxes and to 'high' (350 ind. $0.11 \mathrm{~m}^{-2}$ ) or 'moderate' (220 ind $0.11 \mathrm{~m}^{-2}$ ) numbers in the other half. The experiment was run for $63 \mathrm{~d}$. At termination of the experiment, a mean number of 90 and 36 ind. box ${ }^{-1}$ had migrated into the low density side of the box from the high density and moderate density side, respectively. Significantly higher migration rates per individual were observed from the high density side compared to the moderate density side. The migration rate was estimated from a diffusion coefficient based on the 'Random Walk' theory. No significant differences in migration rates were observed between fed and starved boxes, indicating that dispersal was primarily density-dependent rather than food-dependent. Based on the diffusion coefficient, a total dispersal of all A. filiformis from the high density side was estimated at $47 \mathrm{~m} \mathrm{~h}^{-1}$. Fed $A$. filiformis had a higher weight and larger gonads than starved brittle stars. A separate experiment was set up to study migratory behaviour. It appeared that $A$. filiformis can move both on the sediment surface and within the sediment. In conclusion, migration in A. filiformis may be a common feature, which may cause a more or less continuous displacement of sediment with significant ecological effects.
\end{abstract}

KEY WORDS: Food Interaction - Competition - Dispersal Random walk

\section{INTRODUCTION}

In many habitats, animal density and biomass are limited by shortage of food. In areas where food is abundant, space may instead be a factor limiting population expansion. Thus, exploitation and interference competition are key factors for species distribution and animal community organization. According to a definition by Mayr (1977), competition evolves when 2 species simultaneously seek an essential resource that is limited in supply, such as food or a place to live. Any factor whose effect becomes more severe as population

\footnotetext{
·E-mail: r.rosenberg@kmf.gu.se
}

density increases is called a density-dependent factor. From an evolutionary perspective, competition may widen the spectrum of species functional behaviour and cause niches between species to diverge in order to reduce competition (Branch 1984).

Most experimental studies of density, predation and food availability as regulating factors in marine benthos have so far been restricted to shallow coastal and intertidal areas. Pioneering field studies were initiated in the 1950s on rocky bottom barnacle populations (Southward 1991), which were followed by experimental investigations in the 1960 s and early $1970 \mathrm{~s}$ (e.g. Paine \& Vadas 1969, Connell 1974, Ebert 1977). In the 1970s, investigations into the structuring factors of marine soft-bottom communities were initiated, often 
in manipulative field or laboratory experiments. In such a study, Woodin (1974) demonstrated that competition for space and food was not a significant factor between tube-building polychaetes or between tube builders and burrowing polychaetes. In an experiment with suspension-feeding bivalves, Peterson (1982) did not find any interspecific effect on growth, whereas strong intraspecific density effects on growth and gonad development were recorded. In another study performed in the same subtidal lagoon with other filter-feeding bivalves, Peterson \& Andre (1980) found significant interspecific competition for space. Thus, interference and resource competition are important structuring factors for soft-bottom shallow water communities, but may be significantly different depending upon which species and which functional groups (e.g. suspension feeders, surface and sub-surface deposit feeders, and carnivores) are present in the sediment.

In the marine environment, strong spatial gradients occur from highly productive coastal and estuarine areas to offshore deep areas with poor food supply. In the food-abundant end of such a gradient, benthic communities are rich in numbers and biomass, whereas these attributes gradually decline towards the impoverished end-point (Pearson \& Rosenberg 1987). Quantity and quality of food generally attenuate with depth, and, in most sublittoral sediments, depositfeeding animals have to compete for limited food resources (Levinton 1979, Jumars \& Wheatcroft 1989). Based on data from field samples, it has been suggested that over large sea areas, such as the North Sea, the Skagerrak and the Kattegat, sublittoral macrobenthic communities are limited by insufficient food supply (Josefson 1985, Rosenberg 1995). Temporarily, food may be abundant, for example, following a spring or autumn phytoplankton bloom. In shallow waters, however, suspension feeders may not experience any food limitation during seasons with high production of phytoplankton (Moller \& Rosenberg 1983, Olafsson $1986\}$.

In some localized parts of the North Sea and the Skagerrak, enhanced numbers and biomasses of benthic fauna have been recorcled. For example, in an area with tidal fronts off the Dutch coast, high sedimentation supports a rich benthic infauna (Creutzberg et al. 1984). Similarly, off the Swedish west coast in the Deep Trench, advective near-bottom processes distribute enough food to support a rich benthic fauna with very large biomasses dominated by the brittle star Amphiura filiformis (Rosenberg 1995). Thus, species like $A$. filiformis appear to be more densely packed in the sediment when food occurs super-abundantly compared to when food is less common. Quantity and quality of food are fundamental factors underlying the structure, abundance and biomass of marine benthic communities (Pearson \& Rosenberg 1987, Olafsson et al. 1994).

Amphiura filiformis is one of the dominant macrofaunal species on soft-bottoms in the north-east Atlantic at depths from about $15 \mathrm{~m}$ down to $100 \mathrm{~m}$ or more; it has shown long-term stability and a life span of $20 \mathrm{yr}$ or more (O'Connor et al. 1983, Künitzer et al. 1992. Sköld et al. 1994). This species is buried in the sediment with its disk at about $4 \mathrm{~cm}$ depth. One or 2 arms are stretched up above the sediment for feeding. A. filiformis can switch between suspension and deposit feeding depending on current speed and availability of food (Buchanan 1964). A. filiformis appears to be stationary for long periods, but has been observed to leave its position in the sediment during spawning (Woodley 1975) and when oxygen saturation declines below 13\% (Rosenberg et al. 1991). Thus, this species, which does not move daily in search of food, seems suitable for conservative assessments of densitydependent or space-dependent dispersal of a marine sublittoral population.

In this study, we address the question of whether benthic sublittoral infauna may show density-dependent migration and how this eventually may be related to availability of food. Samples of the dense Amphiura filiformis (about 2250 ind. $\mathrm{m}^{-2}$ ) community from the Deep Trench in the Skagerrak were collected together with its intact sediment for laboratory experiments. A. filiformis were initially manipulated to form 1 high and 1 moderate density treatment, each able to migrate to a less densely populated portion of the sediment. Dispersive behaviour was examined. The animals in these treatments were either given food in super-abundance or were starved.

The measurement of dispersal in this study was analyzed as a 'Random Walk' from high to low density and from moderate to low density, respectively. Should the starved and crowded population of Amphiura filiformis migrate to the less densely populated part of the sediment, this would suggest density-dependent and/or starvation induced dispersion. Should the fed and crowded animals also migrate to the less crowded section of sediment, this would suggest that densitydependence is the primary factor for dispersion rather than competition for food.

\section{MATERIAL AND METHODS}

Sediment collection. Sediment with intact fauna was collected on the western slope of the Deep Trench $\left(57^{\circ} 54.63^{\prime} \mathrm{N}, 11^{\circ} 13.98^{\prime} \mathrm{S}\right)$ in the southeast Skagerrak off the Swedish west coast at $86 \mathrm{~m}$ depth on 13 September 1995. The sampler was a USNEL spade-corer $(-700 \mathrm{~kg})$ inside which transparent plexiglass boxes 
$(47 \times 47 \mathrm{~cm}$, height $39 \mathrm{~cm})$ were installed before each deployment (Berge et al. 1986). When on board, each of the 16 boxes for the experiment was closed at the bottom. One additional sample was taken and the animals retrieved on a $1 \mathrm{~mm}$ mesh were identified and counted. The sediment in the samples was $\sim 25 \mathrm{~cm}$ high with $\sim 15 \mathrm{~cm}$ of water above the sediment. The water in all boxes was aerated with air-stones until connected to a flow-through sea water system in a thermoconstant $\left(10^{\circ} \mathrm{C}\right)$ experimental room at Kristineberg Marine Research Station. Each box was continuously flushed with 2 to $2.51 \mathrm{~min}^{-1}$ sea water $\left(13\right.$ to $6^{\circ} \mathrm{C}$ and 34 psu, similar to natural conditions) of an almost laminary flow of water $\left(0.25\right.$ to $\left.0.30 \mathrm{~cm} \mathrm{~s}^{-1}\right)$ close to the surface of the sediment. The water was pumped from $35 \mathrm{~m}$ water depth and generally contained very little seston. The animals in the boxes were acclimated until 2 October.

Experimental densities. A 2-factorial experimental design replicated 4 times (16 boxes) was used with food in 2 levels (fed or starved) and density at 2 levels (moderate or high; Fig. 1). Dispersal was measured as changes in abundance. To be able to manipulate the number of Amphiura filiformis, but with the rest of the benthic community and sediment intact, flushing of the boxes was cut off for $24 \mathrm{~h}$. By means of this treatment, hypoxic conditions were produced and approximately half of the $A$. filiformis population and several other species appeared on the sediment surface within $24 \mathrm{~h}$. Each box was divided into 2 halves with a cardboard barrier. All specimens of $A$. filiformis and $A$. chiajei with their disk visible on the sediment surface were removed from one side of each box, which is referred to as the side with 'low' density. On the other side of the box, 1 'high' or 1 'moderate' density level of $A$. filiformis was prepared. By counting the number of remaining brittle star arms visible at the sediment surface on the 'low' density side of each box ( 160 arms, $\mathrm{SD}=53$ ), the number of amphiurids 'hidden' in the sediment was estimated to about 900 ind. $\mathrm{m}^{-2}$. On the other sides of the boxes, a high density of $A$. filiformis was established in 8 boxes (350 ind. equal to $~ 3200$ ind. $\mathrm{m}^{-2}$, including the estimated number of burrowed specimens). Moderate densities were established in the other 8 boxes ( 220 ind. equal to -2000 ind. $\mathrm{m}^{-2}$, including the estimated number of burrowed specimens as above). Densities were manipulated during 1 d. A. filiformis and $A$. chiajei were not distinguished during this process. A few large sea urchins Brissopsis lyrifera emerged on the sediment surface during hypoxia; these were removed from the boxes. The high density treatment represents natural densities; numbers were only adjusted to be similar in all aquaria. All treatments were randomized in the boxes. As soon as treatments were finished, the boxes were flushed as before, and all infauna buried into the sediment within $1 \mathrm{~h}$. After $24 \mathrm{~h}$, the cardboard barriers were removed. The vast majority of $A$. filiformis were adults with a mean oral width (Sköld et al. 1994) of $2.5(\mathrm{SD}=0.11$ ) $\mathrm{mm}$, equal to a disk mean diameter of $8.0 \mathrm{~mm}$.

Food treatment. Eight boxes, 4 with high and 4 with moderate densities in half of the boxes, were starved during the experiment (Fig. 1). Of the other 8 boxes, animals in the high density treatments were fed daily with $25 \mathrm{~g}$ frozen, chopped spinach (equal to $3.1 \mathrm{~g} \mathrm{C}$ $\mathrm{m}^{-2}$ ), and the boxes with moderate density with $10 \mathrm{~g}$ spinach (equal to $1.2 \mathrm{~g} \mathrm{C} \mathrm{m}^{-2}$ ). The food was equally spread on the sediment surface in the whole box, i.e. also in the side with low density. Spinach has proven to be a high quality food for marine animals ( $\AA$ kesson 1975). When food was introduced, Amphiura filiformis immediately became active and their arms dragged food into the sediment. In the areas with high or low density, almost all spinach had disappeared within an hour. Spinach left on the sediment surface after $2 \mathrm{~h}$ was removed. The amount of food suspended in the incoming and outgoing water of the boxes was measured in 3 randomly chosen boxes 8 times and no difference was found, which suggests that food supply via the flow-through water system was insignificant compared to the food added to the boxes. For the whole period (63 d) the amount of food given was 194 and $78 \mathrm{~g} \mathrm{C}$ $m^{-2}$, respectively.

A crude estimate of food requirements of Amphiura filiformis, the dominant species in both abundance and biomass (see below), can be calculated based on an energy budget for $A$. filiformis in the Skagerrak. This budget gives an energy need of $0.29 \mathrm{mg} \mathrm{C}$ ind.-1 $\mathrm{d}^{-1}$ based on an absorption efficiency of $70 \%$ (Loo \& Rosenberg 1996). Thus, the energy requirement for the experimental period for high densities of $A$. filiformis would be $58 \mathrm{~g} \mathrm{C} \mathrm{m}^{-2}$ and for moderate densities $36 \mathrm{~g} \mathrm{C}$ $\mathrm{m}^{-2}$ The next ranked species in biomass in the Deep Trench, A. chiajei, with about one-tenth of the biomass of $A$. filiformis (Rosenberg 1995), has a metabolic activity significantly smaller than that of $A$. filiformis (Buchanan 1964). This species would therefore not add extra relative weight to the budget calculations. Thus, the amounts of food given to the high and moderate densities, based on these calculations, were approximately 3.3 and 2.1 times greater than the populations of A. filiformis needed for their basic metabolism. This population alone made up $>70 \%$ of the macrofaunal biomass at the station where the sediment for the experiments was taken (Rosenberg 1995), which sug gests that the quantity of food given to these groups was more than required. Thus, food was not a limiting factor in either food treatment.

Number of animals and assessment of gonads. The experiment was started on 4 October 1995 and termi- 
nated after 63 d on 6 December At the end of the experiment, 4 samples ( 2 from each side of the boxes) were taken in all treatments with a core (diameter $0.012 \mathrm{~m}^{-2}$ ) down to the bottom of the boxes (Fig. 1) and sieved (1 mm meshes). Amphiura filiformis were counted and weighed alive to obtain their individual wet weights. The presence of gonads at the dorsal side of the disks was crudely assessed by eye.

Migratory behaviour. Migratory behaviour was studied in a separate experiment, in which 80 Amphiura filiformis were added to one half of each of 2 aquaria $(20 \times 40 \mathrm{~cm})$ with sieved sediment to remove macrofauna. The aquaria were connected to the flow-through sea water system as above. To cancel out any current influences, brittle stars were added downstream of the empty half in one aquarium and upstream in the other. Activity on the surface was continuously recorded by video ( 5 images $\mathrm{s}^{-1}$ ) in infrared radiation (IR) light in constant darkness for $4 \mathrm{wk}$. After this period, $5 \mathrm{~cm}$ vertical sections of sediment were sieved to assess any sub-surface migration of the brittle stars.

Measurements of sediment. Redox potential was measured with a digital potentiometer at the end of the experiment. Sediment was obtained by pushing 2 plexiglass cores with an inner diameter of $46 \mathrm{~mm}$ into each side of each of the 16 boxes. Ten platinum electrodes $(\varnothing: 1 \mathrm{~mm})$ were pressed through sealed predrilled holes in the cores from $1 \mathrm{~cm}$ above sediment surface down to a depth of $8 \mathrm{~cm}$ below the sediment surface. Calculations of redox potential (Eh) followed those outlined in Fenchel (1969).

At the beginning and end of the experiment, samples of sediment were taken down to $5 \mathrm{~cm}$, using a cut-off syringe $(\varnothing: 1.4 \mathrm{~cm})$. Sediment was freezedried and nitrogen and total carbon were analyzed with a NA $1500 \mathrm{NC}$ analyzer (Fisons).

Calculations and statistics. Mean migration fluxes of Amphiura filiformis between sides in each box were calculated from estimates of abundance in the 4 core samples taken at the end of the experiment in each box (2 from each side of the box; Fig. 1). Numbers obtained in these cores were subtracted from the abundances in the respectively sides of the box estimated at the start of the experiment. To test the hypothesis of densitydependent migration, a 'Random Walk' model was used. In this model, in which the A. filiformis migration is assumed to be a diffusion process, eventual differences in migration rates (net fluxes) between high or moderate densities and low density can be assessed. This is done by calculating a diffusion coefficient based on a solution of Fick's equation for dispersal between 2 compartments (Berg 1983).

$$
C_{(x, t)}=\frac{C_{0}}{2}\left[1+\text { errorfunction }\left(\frac{x}{\sqrt{4 D t}}\right)\right]
$$

In this equation, $C_{0}$ (ind $\mathrm{m}^{-2} \mathrm{~h}^{-1}$ ) is the initial density, $C_{(x, t)}$ (ind. $\left.\mathrm{m}^{-2} \mathrm{~h}^{-1}\right)$ is the density at the end of the experiment, $D\left(\mathrm{~m}^{2} \mathrm{~h}^{-1}\right)$ is the diffusion coefficient which is scale- and density-independent, $t\left(\mathrm{~h}^{-1}\right)$ is the time between start and end and $x(\mathrm{~m})$ is the distance between samples $\left(0.24 \mathrm{~m}_{\mathrm{i}}\right.$ Fig. 1). For each box, the diffusion coefficient $D$ was solved numerically using a mathematics software (MATLAB 4.2). There is a risk of overestimating the diffusion coefficient when the distance between samples is small in relation to steplength between turns in 'Random Walk' models. This should not be the case in the present study, because the distance between individuals was much shorter than the distance between samples. The diffusion model used here assumes that the tendency to move should be equal in all directions, that the sides of the boxes act as reflective surfaces and that there is no interaction between individuals.

Analyses for differences in the diffusion coefficient of Amphiura filiformis and mean individual wet weight between treatments were done as a 2-way analysis of variance (ANOVA) with density and food as fixed factors. Analysis for differences in $\mathrm{N}$-content and total $\mathrm{C}$-content in the sediment at 1 and $5 \mathrm{~cm}$ depth and mean redox potential between the surface and $8 \mathrm{~cm}$ depth were done using a nested 4 -way ANOVA with boxside, density and food as fixed factors and box nested in the combinations of density and food. Homogeneity of variances was examined using Cochran's $C$ test ( $p<0.05$; Snedecor \& Cochran 1967) and heterogeneity was removed by $\ln x$ transformation.

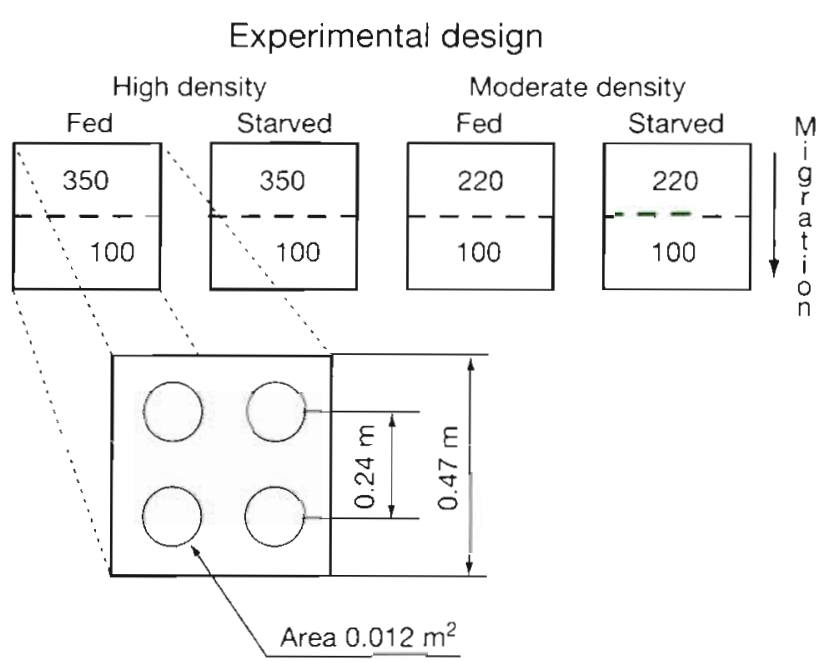

Fig. 1. The 2-factorial experimental design with high and moderate density of Amphiura filiformis and fed and starved treatments. Eventual migration route is from the high ( 350 ind.) or moderate ( 220 ind.) density side of the box to the low (100 ind.) density side. $n=4$ replicates of each treatment. The enlarged box below shows how core samples were taken at the end of the experiment. The estimated distance between cores $(24 \mathrm{~cm})$ was used in the 'Random Walk' calculation 


\section{RESULTS}

\section{Sediment, redox potential, and carbon and nitrogen content}

At the end of the experiment, the sediment surface in all boxes was generally grey-brown in colour and generally similar to its appearance at the start. Some dark spots were, however, noted in the corners of boxes with the highest densities of brittle stars. The vertical appearance of the sediment, visually inspected from the sides of the transparent boxes, seemed unchanged. A significantly smaller mean redox potential $(0$ to $8 \mathrm{~cm}$ depth) was measured in the fed treatments than in the starved treatments (Fig. 2; ANOVA, $p<0.05, \mathrm{df}=1,12$ ). No significant difference in mean redox potential was observed between treatments with moderate and high densities (ANOVA, $p>0.05, \mathrm{df}=1,12$ ). Data from May 1995 are also shown for comparison with measurements made in sediment cores in the field from the same area.

Mean total carbon and nitrogen in the top 0 to $1 \mathrm{~cm}$ sediment at the beginning of the experiment were $3.3 \%(\mathrm{SD}=0.13)$ and $0.25 \%(\mathrm{SD}=0.018)$ of sediment dry weight, respectively $(C / N=13.2)$. These values were not significantly different from those of the 5 to $6 \mathrm{~cm}$ layer At the end of the experiment, no significant differences were found between treatments (ANOVA, $\mathrm{p}>0.05$, df $=1,12$ ). Thus, no accumulation of total carbon or nitrogen occurred in the sediment during the experiment.

\section{Faunal composition}

Mean abundances of the 10 dominant species recorded in the high and moderate treatments at the end of the experiment are shown in Table 1. The numerically highest ranked species were the same in both treatments. A pair-wise comparison of the abundance of each species shows that the numbers were slightly greater in the high density treatment compared to the moderate treatment, except for the gastropod Hyala vitrea. The numbers in the boxes were also similar to those found in the field and indicative of low experimental mortality. Only a few dead individuals were found during the experiment. Conspicuous species observed on the sediment surface at the end of the experiment were the ophiuroid Ophiura albida (total 9 ind. in all boxes). the polychaete Ophiodromus flexuosus

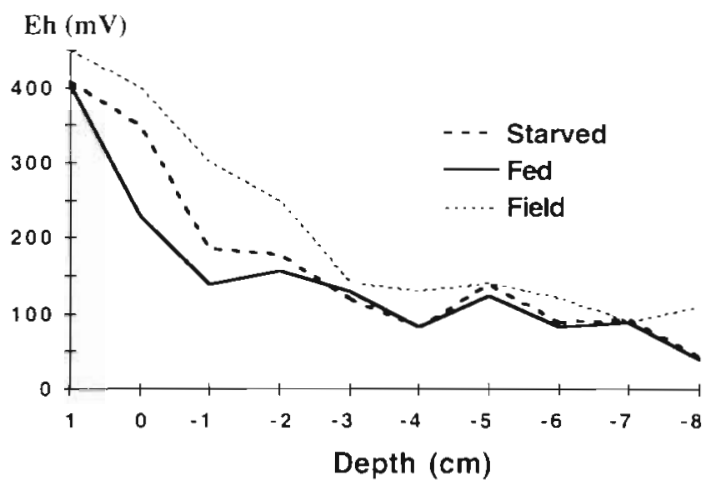

Fig. 2. Mean redox potentials ( $E h ; n=32$ ) in relation to depth of sediment at the end of the experiment (December 1995) in the fed and starved treatments, and in sediments collected in the field (May 1995, S. Agrenius pers. comm.)

(1 to 4 per box), a single anemone Cerianthus sp. and the amphipod Maera loveni. Amphiura filiformis made up an average of $95.5 \%$ and A. chiajei $4.5 \%$ of the total density of amphiurids

\section{Dispersal}

The mean net flux of Amphiura filiformis from the sides of the boxes with high or moderate densities to the sides with a low density is shown in Fig. 3. No significant interaction was found between the density and food treatments (ANOVA, $\mathrm{p}>0.05, \mathrm{df}=1,12$ ). Significantly (ANOVA, $p<0.05$, df $=1,12$ ) greater diffusion coefficients, indicating faster dispersal per specimen, were observed in boxes with high densities (mean $6.136 \times 10^{-5} \mathrm{~m}^{2} \mathrm{~h}^{-1}$ ) than in boxes with moderate densities (mean $1.801 \times 10^{-5} \mathrm{~m}^{2} \mathrm{~h}^{-1}$ ). No significant (ANOVA, $\mathrm{p}>0.05, \mathrm{df}=1,12$ ) differences in diffusion coefficients were observed between fed and starved treatments.

Table 1. Mean (SD) density per $\mathrm{m}^{2}$ of 10 dominant species found in the high and moderate density treatments at the end of the experiment, and initial numbers found in the field

\begin{tabular}{|lccc|}
\hline & High density & Moderate density & Field density \\
\hline Amphiura filiformis & $2322(840)$ & $1552(560)$ & 2250 \\
Pholoe minuta & $990(52)$ & $792(52)$ & 861 \\
Mysella bidentata & $797(85)$ & $667(59)$ & 278 \\
Abra nitida & $458(96)$ & $359(11)$ & 389 \\
Lapidoplax buskii & $260(15)$ & $245(55)$ & 194 \\
Hyala vitrea & $57(26)$ & $135(7)$ & 56 \\
Ophiura albida & $83(22)$ & $68(18)$ & 0 \\
Pectinaria koreni & $104(0)$ & $62(7)$ & 0 \\
Pectinaria auricoma & $78(11)$ & $42(0)$ & 0 \\
Heteromastus filiformis & $94(0)$ & $10(7)$ & 28 \\
\hline
\end{tabular}




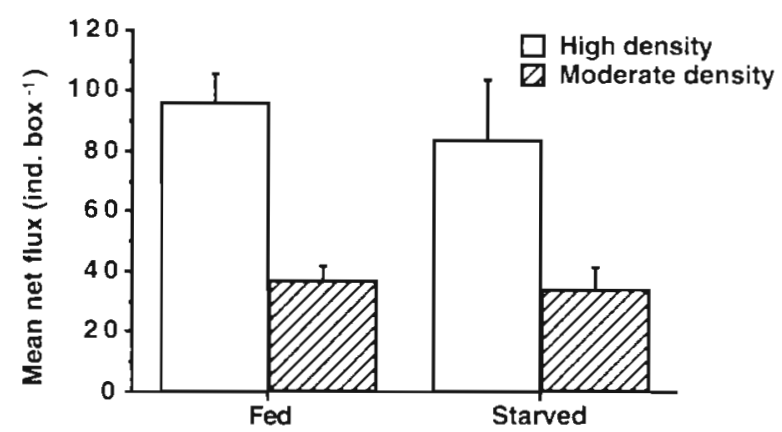

Fig. 3. Amphiura filiformis. Mean (SD; $\mathrm{n}=4$ ) rates of migration (net fluxes after 63 d) from the half of a box with high or moderate density to the half with low density in fed and starved treatments

\section{Biomass}

Individual weights of Amphiura filiformis are shown in Fig. 4. A. filiformis fed during the experiment had a significantly (ANOVA, $p<0.05$, df $=1,12$ ) greater wet weight per individual than those that were starved. No significant difference (ANOVA, $p>0.05$, df $=1,12$ ) in weight was found between individuals in moderate (mean $0.202 \mathrm{~g} \mathrm{ind.}^{-1}$ ) and high (mean $0.201 \mathrm{~g} \mathrm{ind.-}^{-1}$ ) densities, or between sides of a box. Thus, $A$. filiformis assimilated the food they were given and in about equal amounts per individual in both density treatments.

\section{Gonad development}

Several Amphiura filiformis showed visible development of gonads on the ventral side of the disk. Conads were observed in $42 \%(\mathrm{SD}=14, \mathrm{n}=26)$ of the fed brittle stars and in $12 \%(\mathrm{SD}=15, \mathrm{n}=25)$ of the starved individuals

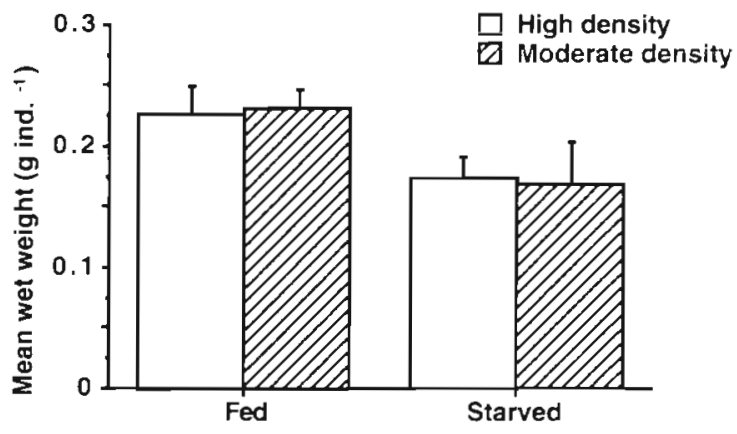

Fig. 4. Amphiura fillformis. Mean ( $\mathrm{SD} ; \mathrm{n}=4)$ individual wet weight in high and moderate densities and in fed and starved treatments

\section{Migratory observations}

No brittle stars were seen on the surface of the sediment in the boxes. When the behaviour was recorded by video, 14 Amphiura filiformis were observed moving on the sediment during the 4 wk of continuous observation. Some of these crossed the 'borderline' to the side of the 2 aquaria with no macrofauna, but some moved back and only 4 buried themselves into the sediment on the 'empty' side. In the analysis of sediment at the end of this experiment, 16 individuals out of 160 were found on the formerly 'empty' side; 8 of these were found more than $10 \mathrm{~cm}$ from the 'borderline'. There was no upstream or downstream effect on migration. Thus, A. filiformis are able to move on or within the sediment.

\section{DISCUSSION}

\section{Experimental technique and food supply}

The experimental technique used here, with natural sediment and fauna, was adopted from Berge et al. (1986). In the present experiment, the aquaria were supplied with water of the same salinity and a similar temperature as that at the site of collection. Except for the surface of the sediment, carbon and nitrogen concentrations and redox potential depth distribution were similar in the treatments. At the upper centimetres of the sediment, the redox potential was lower, probably as a result of food supply. Thus, sediment conditions seem to have been rather stable during the experimental period despite different treatments. No great differences were recorded in composition and abundance of dominant species, either between treatments at the end of the experiment, or between treatments and what was initially found in the field. In comparison with abundances obtained in May 1992 from the same area (Rosenberg 1995), the numbers were similar, except for Amphiura filiformis, which then occurred in larger numbers of about 3600 ind. $\mathrm{m}^{-2}$.

'Export production', which is similar to sedimentation, has in the Skagerrak been estimated to be about $50 \mathrm{~g} \mathrm{C} \mathrm{m}^{-2} \mathrm{yr}^{-1}$ (Stigebrandt 1991), whereas records from sediment traps during the productive part of the year have given estimates 2 to 3 times greater (Rosenberg et al. 1990, Bjørnsen et al. 1993). These quantities of sedimenting material towards the bottom are small compared to the amounts used in this experiment. Thus, the total amount seems to have been more than sufficient for all animais in the experiment. In the Deep Trench area, however, advective transport of organic matter has been recorded near the bottom. This will provide additional food to the benthic communities living there (Rosenberg 1995). 


\section{Pattern of distribution}

The 'ideal free distribution' model is frequently used to describe patterns of distribution of mobile animals in relation to availability of food (Milinski 1988, Kacelinic et al. 1992). It states that each individual should choose patches so that it maximises its rate of food intake, that resources are distributed in patches and that competitors are equal in all respects. The model may be applicable to behavioural patterns in mobile animals such as fish, which can make a clear choice in this respect. It is, however, less relevant for semi-mobile benthic infauna that may not be able to notice and respond to resources some distance away.

Instead, Amphiura filiformis may be moving randomly. In the present experiment, some individuals may be pushed towards the sides of the boxes and may either have to stay close to the walls or to 'push back' and perhaps create pressure for movement in the opposite direction. Density-dependent dispersal in the present experiments occurs from the open half of the box where the brittle stars can move into the less densely populated side. From this borderline, the net migration will initially be more or less unidirectional. Limited by the 3 sides of the enclosure, this general behaviour pattern seems to fit the diffusion model, which states that dispersal arises from random movements and that net movement results in a more even spread of a population (e.g. MacCall 1990). If the movements of some individuals were retarded along the sides or in the 2 corners of boxes, the diffusion coefficient should have been underestimated. If that happened, however, it may not have affected the difference in rate of dispersal between the 2 densities.

In this experiment, $26 \%$ (high) to $16 \%$ (moderate) of the individuals in the crowded side of the boxes had moved into the less crowded side by the end of the experiment. As this only indicates the net flux of specimens in a 'Random Walk' model, the total movement of specimens in the sediment should be greater. A simple calculation of the capacity of Amphiura filiformis to rework and dislocate the sediment could be estimated from the diffusion coefficient observed in this study $\left(D=6.136 \times 10^{-5} \mathrm{~m}^{2} \mathrm{~h}^{-1}\right.$, in high density) and from field data abundance (density of -3000 ind $\mathrm{m}^{2}$ ) obtained from the Deep Trench in the Skagerrak (Rosenberg 1995). Given in 2 dimensions, the square of the distance of dispersal during $1 \mathrm{~h}$ from a point of origin is $\mathrm{r}^{2}=4 D t=$ $4 \times 6.136 \times 10^{-5} \mathrm{~m}^{2} \mathrm{~h}^{-1}$ (Berg 1983). This gives a total distance of movement of $47 \mathrm{~m} \mathrm{~h}^{-1}$ for all 3000 specimens of $A$. filiformis in a square metre. Such an estimate is a crude approximation because the distance is dependent on patterns, direction and speed of movement. At a density of about 3000 ind. $\mathrm{m}^{-2}$, the area of sediment at about 3 to $4 \mathrm{~cm}$ depth covered by disks of $A$. filiformis can be estimated as $22 \%$ (Rosenberg 1995). The capacity of such a density of brittle stars to displace sediment can be calculated at $0.18 \mathrm{~m}^{2} \mathrm{~h}^{-1}$. Thus, movement of $A$. filiformis should generate a more or less continuous displacement of sediment and be of great significance to the bio-geo-chemical processes in the sediment.

\section{Food and density dependence}

Several studies dealing with soft-bottom fauna have shown food to be a regulating factor for density. This is most obvious for deposit-feeding animals, which have to compete for food as a partly degraded resource (e.g. Levinton 1979). In shallow waters, suspension-feeding animals may, at least during some seasons, be able to feed on an abundant, nutritious food source. Although secondary production in suspension-feeding bivalves can be extremely high in some areas (Möller \& Rosenberg 1983), other studies have demonstrated that members of this feeding category can also be food limited (Peterson \& Black 1987).

In the present experiment, the weight of Amphiura filiformis treated with daily additions of food increased significantly more than that of starved individuals. Thus, the brittle stars assimilated the food and some of the resulting energy was allocated to germinal growth. Build-up of gonads may be a way for A. filiformis to store energy, which may be resorbed during periods of starvation. In a similar box experiment with a benthic community from the same Deep Trench area, Sköld \& Gunnarsson (1996) demonstrated somatic and germinal growth in $A$. filiformis and $A$. chiajei in response to food supply. Comparisons between a high and a low density community in that experiment suggested that growth was density-dependent because of competition for space or food. A possible explanation for that density-dependent growth may be that the amount of food ( $16.8 \mathrm{~g} \mathrm{C} \mathrm{m}^{-2}$ in $2.5 \mathrm{mo}$ ) given to the high density treatment was not enough. It was slightly less than one-tenth of the amount (in carbon) given in the high density treatment in the present study. Contrary to the results in the Sköld \& Gunnarsson (1996) experiment, Josefson (1995) found that growth was independent of density even in A. filiformis at densities $>3000$ ind. $\mathrm{m}^{-2}$. These results were obtained in a field study in the Kattegat (south of Skagerrak) and growth of A. filiformis was estimated from measurements taken $143 \mathrm{~d}$ apart of oral widths. The reason for density-independent growth rates may be that abundances were related to the food resources in the sampling areas and that food availability per individual was approximately equal. Josefson's (1995) estimates of biomass increments were obtained from size correlations; growth of gonads was not included. 
Based on results from a field study, it has been suggested that the benthic community examined in the present study is limited by space rather than by food (Rosenberg 1995). This assumption was made because several populations, among them Amphiura filiformis, had extremely large densities and biomasses. A significant contribution of food for these animals in the field was supplied by means of near-bottom horizontal currents. In our experiments, $A$. filiformis was fed daily with food in excess. Despite this, they migrated from the crowded treatments to sediments where abundance was smaller; numbers and biomasses became similar. This is the first time density-dependent dispersal has been shown experimentally in sublittoral softbottom populations.

\section{Interspecific and intraspecific competition}

In shallow coastal and intertidal areas, densitydependent competition and interaction have been observed in a number of studies. Ambrose (1986), for instance, provided evidence that the avoidance of large densities is a selective advantage in the amphipod Rhenoxynius abronius. Such migration significantly increased the emigration from the sediment to the water column, which increased the vulnerability of amphipods to predation. Based on results from. an experimental study in a sandy-bottom lagoon in southern California, Peterson (1977) suggested that competition for space may be the most important biological factor determining the abundance of species in that area. Manipulations of density demonstrated emigration of a suspension-feeding bivalve, Cryptomya californica, which probably was a result of negative intraspecific interactions. Additional results from the same lagoon also suggested that competition, in this case interspecific interaction among suspensionfeeders, for space is a primary mechanism for interaction in this system (Peterson \& Andre 1980). On the other hand, in an experimental study of spatial competition in a dense infaunal intertidal community on the U.S. Pacific coast, no interspecific competitive interactions could be observed (Wilson 1984). Wilson (1983) found, however, strong density-dependent intraspecific competition in the deposit-feeding polychaetes Pygospio elegans and Pseudopolydora kempi. Although density-dependent migrations have been demonstrated in the field and in microcosm experiments, the importance of the availability of food was not evaluated.

The examples presented here suggest that intra-and interspecific competition can both affect abundance, distribution and organisation of populations. Similar results have also been obtained in studies of intertidal limpets (Creese \& Underwood 1982). Several authors have suggested, based on the fact that the same species compete for the same food resources, that intraspecific (Ebert 1977, Levin 1981) and also intrafamilial (Woodin \& Jackson 1981) competition are stronger and more common than interspecific competition. Competitive interactions between Amphiura filiformis and $A$. chiajei were not investigated here, but these 2 species are known to co-occur in many areas (e.g. Petersen 1913) and also in the Deep Trench sediments (Rosenberg 1995). Interactive behaviour between the 2 species was not observed on the surface of sediments during the experiments. Their disks are at a similar depth in the sediment and interspecific competition for space is likely when densities are high.

Intraspecific aggressive behaviour, e.g. fights for food, has been recorded in the spionid Pseudopolydora paucibranchiata, and recruitment patterns for this species seem to result in a uniform spacing during settlement (Levin 1981). Such territorial behaviour may be a population regulatory factor. Intraspecific aggressive behaviour in Amphiura filiformis was not observed at the sediment surface in the present experiments, but a few times 2 arms belonging to different specimens were noted to struggle with one another when they tried to capture the same food particle. Mutual interference may, however, occur within the sediment. The space occupied by disks of $3000 \mathrm{ind} . \mathrm{m}^{-2}$ of A. filiformis at about $3 \mathrm{~cm}$ depth in the sediment in the Deep Trench was estimated to be $\sim 0.22 \mathrm{~m}^{2}$ (Rosenberg 1995). In addition to this, about 3 arms of each individual are also kept in the sediment (Ockelmann \& Muus 1978, Loo et al. 1996), which indicates that the space in the sediment may be densely packed with $A$. filiformis. For feeding, A. filiformis needs access to the surface; the area swept and occupied by the arms (sometimes 2 per individual) is larger than the disc area.

Peterson (1977) argued that the carrying capacity of infauna is only loosely associated with total volume of infauna, but more closely related to demand for contact with the water-column. It is impossible to determine whether or not the trigger for dispersal of Amphiura filiformis in the present experiment is interaction on the surface or within the sediment. Numerous encounters between arms on the surface may trigger movement of the animals. The activity pattern and frequency of encounter rates of arms in the sediment are not known. When food was presented to the brittle stars, the activity of arms increased immediately. This increased activity increases the encounter rates between neighboring specimens and possibly induces migratory behaviour. Thus, if this is the case, increased arm activity may have a positive impact on the rate of migration and may lead to an overestimation of the diffusion coefficient. 
Migration of brittle stars is shown to occur on the surface and within the sediment. Movement within the sediment takes longer, but the risk of predation from surface-dwelling predators is less compared to migration on the surface. That brittle stars are well suited to move in the sediment was demonstrated in the initial phase of the experiment; they were able to burrow into the sediment within a few seconds. The arms (usually 3 ) kept in the sediment may act as an anchoring system (Woodley 1975) and for Amphiura chiajei have been suggested to assist in sliding movements of the animals within the burrows (Ockelmann \& Muus 1978). According to Woodley (1975), it is possible that brittle stars can drag themselves through the substratum in the same way that they burrow. The present experiment provides new evidence that brittle stars are mobile and may use their arms in the sediment to adjust their position and to direct their movement, perhaps sometimes away from interfering animals. The substantial migration by $A$. filiformis in this laboratory experiment might imply that they commonly move in the sediment and change their position. Such movement will destabilize the sediment and, as a consequence, affect other infauna behaviour including settlement and recruitment. Displacement will have impacts on chemistry and compaction of sediments. Because A. filiformis is a conspicuous species in many areas of the east Atlantic (e.g. Petersen 1915, Duineveld et al. 1987), these suggested effects may be of significant importance to the ecosystem and need to be investigated in detail in future studies.

\section{Colonization}

The observed mobility of Amphiura filiformis implies that this species is capable of colonizing new patches, at least over short distances. Physical disturbances, such as demersal trawling, dredging, strong winds and seasonal deficiency of oxygen in bottom waters, may open new patches for possible immigration by adult A. filiformis. Zajak \& Whitlatch (1991) demonstrated that demographic aspects including survivorship, fecundity, and population growth rate are important factors in soft-sediment patch dynamics. Seasonal hypoxia has been shown to force $A$. filiformis and $A$. chiajei out of the sediment (Rosenberg et al. 1991). The latter species was capable of directional migration on the surface to reach elevated patches (Stachowitsch 1984), where oxygen concentrations were presumably greater than in nearby depressions. Thus, these brittle stars, if they survive a physical disturbance or a hypoxic event, may--when oxygen conditions improve-later be able to emigrate to new patches where exploitable resources may be available.
From 1968 onwards, benthic faunal succession following abatement of sediment enrichment was studied in a Swedish fjord in October for successive years (Rosenberg 1976). In the inner part of the fjord, the benthic communities were in an early successional stage in 1969. No Amphiura filiformis were found in that inner area. In 1970, about 50 juvenile $A$. filiformis ind. $\mathrm{m}^{-2}$ were recorded at 3 stations at $30 \mathrm{~m}$ depth, but the following year several hundred adult $A$. filiformis with developed gonads were found at the same 2 stations (Rosenberg 1976 and unpubl. results). It takes several years for $A$. filiformis to grow to maturity in the Skagerrak (Sköld et al. 1994), so immigrants must have arrived from the adult population further out in the fjord. Emigration from outer stations, where adults were found the previous year in sufficient numbers (Rosenberg 1976), suggests a migration over distances of up to $2 \mathrm{~km}$, which is too long to be the result of a diffusion process only. The diffusion equation used here suggests that migration by means of diffusion may take about 3 million years. Perhaps populations of A. filiformis were present on the slopes surrounding those two $30 \mathrm{~m}$ stations. In any event, immigration of adult $A$. filiformis to this previously low diversity area was evident.

Acknowledgements. The authors thank Per-Olof Moksnes, Per R. Jonsson, Mattias Sköld. Peter Tiselius and Antony Underwood for discussions, suggestions and comments on the manuscript. Financial support for this study was provided by the Swedish Natural Science Research Concil (grant no. B-AA/BU 0329-312), the Swedish Environmental Protection Agency and the Cöteborg University Marine Research Center.

\section{LITERATURE CITED}

Akesson B (1975) Reproduction in the genus Ophryotrotrocha (Polychaeta, Dovilleidae). PSZN I: Mar Ecol 39(Suppl): 377-398

Ambrose WGJ (1986) Experimental analysis of density dependent emigration of the amphipod Rhepoxynus abronius. Mar Behav Physiol 12:209-216

Berg HC (1983) Random walks in biology. Princeton University Press, Princeton, NJ

Berge JA, Schaanning M, Bakke T, Sandøy KA, Skeie GM, Ambrose JWG (1986) A soft-bottom sublittoral mesocosm by the Oslofjord: description, performance and examples of application. Ophelia 26:37-54

Bjornsen KP, Kaas H, Kaas H, Nielsen TG, Olesen M, Richardson K (1993) Dynamics of a subsurface phytoplankton maximum in the Skagerrak. Mar Ecol Prog Ser 95:279-294

Branch GM (1984) Competition between marine organisms: ecological and evolutionary implications. Oceanogr Mar Biol Annu Rev 22:429-593

Buchanan JB (1964) A comparative study of some features of the biology of Amphiura filiformis and Amphiura chiajei (Ophiuroidea) considered in relation to their distribution. J Mar Biol Assoc UK 44:565-576

Connell JH (1974) Ecology: field experiments in marine eco- 
logy. In: Marisal RN (ed) Experimental marine biology Academic Press, New York, p 21-54

Creese RG, Underwood AJ (1982) Analysis of inter- and intraspecific competition amongst intertidal limpets with different methods of feeding. Oecologia (Berl) 53:337-346

Creutzberg F, Wapenaar P, Duineveld G, Lopez Lopez N (1984) Distribution and density of the benthic fauna in the southern North Sea in relation to bottom characteristics and hydrographic conditions. Rapp PV Réun Cons Int Explor Mer 183:101-110

Duineveld GCA, Künitzer A, Heyman RP (1987) Amphiura filiformis (Ophiuroidea: Echinodermata) in the North Sea. Distribution, present and former abundance and size composition. Neth J Sea Res 21:317-329

Ebert TA (1977) An experimental analysis of sea urchin dynamics and community interactions on a rock jetty. J Exp Mar Biol Ecol 27:1-22

Fenchel T (1969) The ecology of marine mucrobenthos IV Structure and function of the benthic ecosystem its chemical and physical factors and the microfauna communities with special reference to the ciliated protozoa. Ophelia $6: 1-182$

Josefson $A B$ (1985) Distribution of diversity and functional groups of marine benthic infauna in the Skagerrak (Eastern North Sea) - Can larval availability affect diversity? Sarsia 70:229-24.9

Josefson AB (1995) Large-scale estimate of somatic growth in Amphiura filiformis (Echinodermata: Ophiuroidea). Mar Biol 124:435-442

Jumars PA, Wheatcroft RA (1989) Responses of benthos to changing food quality and quantity, with a focus on deposit feeding and bioturbation. In: Berger WH, Smetacek VS, Wefer G (eds) Productivity of the ocean: present and past. Wiley \& Sons, London, p 235-253

Kacelinic A, Krebs JH, Bernstein C (1992) The Ideal free distribution and predator-prey populations. Trends Ecol Evol $7: 50-55$

Künitzer A, Basford D, Craeymeersch JA, Dewarumez JM, Dörjes J, Duineveld GCA, Eleftheriou A, Heip C, Herman P, Kingston P, Niermann U, Rachor E, Rumohr H, de Wilde PAJ (1992) The benthic infauna of the North Sea: species distribution and assemblages. ICES (Int Counc Explor Sea) J Mar Sci 49:127-143

Levin LA (1981) Dispersion, feeding behavior and competition in two spionid polychaetes. J Mar Res 39:99-117

Levinton JS (1979) Deposit-feeders, their resources, and the study of resource limitation. In: Livingston RJ (ed) Ecological processes in coastal and marine systems. Plenum Press, New York, p 117-141

Loo LO, Jonsson PR, Sköld M, Karlsson Ö (1996) Passive suspension feeding in Amphiura filiformis (Echinodermata: Ophiuroidea): feeding behaviour in flume flow and potential feeding rate of field populations. Mar Ecol Prog Ser 139: $143-155$

Loo LO, Rosenberg R (1996) Production and energy budget in marine suspension feeding populations: Mytilus edulis, Cerastoderma edule, Mya arenaria and Amphiura filiformis. J Sea Res 35:199-207

MacCall AD (1990) Dynamic geography of marine fish populations. Univ Washington Press, Seattle

Mayr E (1977) Populations, species, and evolution. An abridgment of animal species and evolution. Harvard Univ Press, Cambridge

Milinski M (1988) Games fish play: making decisions as a social forager. Trend Ecol Evol 3:325-330

Möller P, Rosenberg R (1983) Recruiment, abundance and production of Mya arenaria and Cardium edule in marine shallow waters, western Sweden. Ophelia 22:33-55

Ockelmann KW, Muus K (1978) The biology, ecology and behaviour of the bivalve, Mysella bidentata. Ophelia 17 . $1-93$

O'Connor B, Bowmer T, Grehan A (1983) Long-term assessment of the population dynamics of Amphiura filiformis (Echinodermata, Ophiuroidea) in Galway Bay, west coast of Ireland. Mar Biol 75:279-286

Olafsson E (1986) Density dependence in suspension-feeding and deposit-feeding populations of the bivalve Macoma baltica, a field experiment. J Anim Ecol 55:517-526

Olafsson EB, Peterson CH, Ambrose WG (1994) Does recruitment limitation structure population and communities of macro-invertebrates in marine soft sediments: the relative significance of pre- and post-settlement processes Oceanogr Mar Biol Annu Rey 32:65-109

Paine RT, Vadas RL (1969) The effects of grazing by sea urchins, Strongylocentrotus spp, on benthic algal populations. Limnol Oceanogr 14:710-719

Pearson TH, Rosenberg R (1987) Feast and famine: structuring factors in marine benthic communities. In: Gee JHR, Giller PS (eds) The 27th Symposium of The British Ecological Society Aberystwyth 1986. Blackwell Scientific Publications, Oxford, p 373-395

Petersen CGJ (1913) Valuation of the sea. 2. The animal communities of the sea bottom and their importance for marine zoogeography. Rep Dan Biol Annu Rev 16:229-311

Petersen CGJ (1915) On the animal communities of the sea bottom and their importence for marine zoogeography. Rep Dan Biol Stn 16:1-28

Peterson CH, Black R (1987) Resource depletion by active suspension feeders on tidal flats: influence of local density and tidal elevation. Limnol Oceanogr 32:143-166

Peterson $\mathrm{CH}$ (1977) Competitive organization of the softbottom macrobenthic communities of southern California lagoons. Mar Biol 43:343-359

Peterson $\mathrm{CH}$ (1982) The importance of predation and intraand interspecific competition in the population biology of two infaunal suspension-feeding bivalves, Protothaca staminea and Chione undatella. Ecol Monogr 52:437-475

Peterson $\mathrm{CH}_{1}$ Andre SV (1980) An experimental analysis of interspecific competition among marine filter feeders in a soft-sediment environment. Ecology 61:129-139

Rosenberg R (1976) Benthic faunal dynamics during succession following pollution abatement in a Swedish estuary. Oikos 27:414-427

Rosenberg R (1995) Benthic marine fauna structured by hydrodynamic processes and food availability. Neth J Sea Res 34:303-317

Rosenberg R, Dahl E, Edler L, Fyrberg L, Granéli E, Granéli W, Hagström $\AA$, Lindahl $O$, Matos MO, Pettersson $K_{1}$ Sahlsten E, Tiselius P, Turk V, Wikner J (1990) Pelagic nutrient and energy transfer during spnng in the open and coastal Skaferrak. Mar. Ecol Prog Ser 61:215-231

Rosenberg R, Hellman B, Johansson B (1991) Hypoxic tolerance of marine benthic fauna. Mar Ecol Prog Ser 79: $127-131$

Sköld M, Gunnarsson J (1996) Somatic and germinal growth of the infaunal brittle stars Amphiura filiformis and Amphiura chiajei in response to organic enrichment. Mar Ecol Prog Ser 142:203-214

Sköld M, Loo LO, Rosenberg R (1994) Production, dynamics and demography of an Amphiura filiformis population. Mar Ecol Prog Ser 103:81-90

Snedecor GW, Cochran WG (1967) Statistical methods. Univ Iowa Press, Ames

Southward AJ (1991) Forty years of changes in species com- 
position and population density of barnacles on a rocky shore near Plymouth. J Mar Biol Assoc UK 7 1:495-513

Stachowitsch M (1984) Mass mortality in the Gulf of Trieste: The cource of commity destruction. PSZN I: Mar Ecol $5: 243-264$

Stigebrandt A (1991) Computations of oxygen fluxes through the sea surface and the net production of organic matter with application to the Baltic and adjacent seas. Limnol Oceanogr 36:444-454

Wilson WHJ (1983) The role of density dependense in a marine infaunal community. Ecology 64:295-306

Wilson WHJ (1984) An experimental analysis of spatial com-

Editorial responsibility: Otto Kinne (Editor),

Oldendorf/Luhe, Germany petition in a dense infaunal community: the importance of relative effects. Estuar Coast Shelf Sci 18:673-684

Woodin SA (1974) Polychaete abundance patterns in a marine soft-sediment environment: the importance of biological interaction. Ecol Monogr 44:171-187

Woodin SA, Jackson JBC (1981) Interphyletic competition among marine benthos. Am Zool 19:1029-1043

Woodley JD (1975) The behaviour of some amphiurid britlestars. J Exp Mar Biol Ecol 18:29-46

Zajak RN, Whitlatch RB (1991) Demographic aspects of marine, soft sediment patch dynamics. Am Zool 31. $808-820$

Submitted: June 13, 1997; Accepted: September 12, 1997 Proofs received from author(s): November 19, 1997 